\title{
NOTES ON SOURCE MATERIAL
}

This book is intended both for members of the medical profession and for the general public.

Accordingly, while technical data of special interest to physicians have been incorporated, the overall presentation is journalistic. Intriguing relevant data, little-known historical incidents, and some illustrative anecdotes are included with the basic facts.

This broad treatment provides a picture in depth, on many levels, of the medical and public health fields-and simultaneously affords a whole new perspective on Mexico's past and present.

\section{ANNOTATION}

To achieve maximum readability for both medical doctors and laymen, footnotes have been held to a minimum.

For example, some medical terms, but not all, are explained in footnotes. To explain all would be at once time-wasting and irksome to physicians, and tedious and of little real significance to those outside the profession. The less familiar medical terms defined here are chiefly those that either delineate a general subject under discussion or may have some particular interest for laymen. Terminology employed in a (rarely included) technical passage, such as a step-bystep surgical procedure, clearly of importance only to physicians, is not interpreted.

Absence of profuse annotation does not mean that supportive data, references, and explanatory notes have been omitted. Much material that might have been presented in footnote form instead has been embodied in the text.

SOURCE MATERIAL

Sources of information usually are indicated in the text, or in annotation. If unspecified, as some widely known or long-accepted data, the sources ordinarily lie in the relevant books in the Bibliography. 
But it is difficult (in fact, impossible) to enumerate every contributory source. Much miscellaneous and background information was accumulated over a number of years of research for other writing projects. Furthermore, a large part of this book is based on original material, rather than on data gleaned from standard reference works -on the findings of individual doctors, on a long series of interviews with authorities concerned, and on my own investigations and observations in Mexico.

The following are the main categories of source material:

1) Reference books, as itemized in the Bibliography. The Bibliography is a representative listing only, and general reference works consulted, such as encyclopedias and medical texts, are not included.

2) Records of Mexico's Department of Public Health and Assistance. This category includes (in addition to several published volumes named in the Bibliography) the Department's voluminous records and reports on its huge body of routine undertakings, special projects, surveys, vital statistics-complete records on achievements throughout the nation during the 1958-1964 administration of Mexico's President Adolfo López Mateos.

It includes, also, the Department's records on preceding administrations and its archives of historical source material, plus some original documents now in the National Archives, and archeological and anthropological material now at the National Museum of Anthropology.

3) Medical papers (published and unpublished) by individual doctors and medical teams. This category consists of hundreds of often highly technical papers written by medical doctors from Mexico, the United States, and Latin America, reporting to members of their profession on their findings-in laboratory research, animal experimentation, clinical testing, special studies and surveys, significant case histories, results with new treatments, drugs, and surgical procedures-in their particular specialty or field of activity. Most of these papers were published in medical journals or read before medical congresses.

4) Interviews with government officials and doctors. This is another major category of source material. In years of writing about Mexico, I privately interviewed a number of Mexican government officials and most of the nation's leading doctors. These authorities in the medical and public health areas included, of course, numerous officials in the Department of Public Health and Assistance; officials 
of the Mexican Institute of Social Security; officials of the Institute of Security and Social Services of the Workers of the State; directors and sub-directors at the National Institute of Cardiology, the National Institute of Tropical Diseases, the National Institute of Nutrition, and other national institutions; the rector of the National University; heads of government medical schools; heads of various government hospitals and private hospitals; many doctors in private practice, from specialists in the nation's capital to general practitioners in distant cities and towns. Other officials in different fields that I privately interviewed, discussing matters related in one way or another to medicine or public health, included two former Presidents of Mexico, Lic. Emilio Portes Gil and General Lázaro Cárdenas; several past and present members of presidential Cabinets; senators and deputies.

5) Personal investigations and observations. Some of the material in this book stems from events, incidents, customs, and conditions that I personally investigated, observed at first hand, or experienced in a dozen years of living in Mexico.

6) Published articles. In covering Mexico as a correspondent for U.S. medical publications, I have written and had published over two hundred articles reporting on doctors' activities and findings. Many were based on the doctors' technical papers; others on doctors' speeches and discussions at medical conventions and seminars, or their disclosures to me in private interviews. Some of my articles, originally published in the Medical Tribune (World Wide Medical News Service, Inc., New York City) are incorporated, with minor revisions, in this book.

7) Material provided by Dr. Amézquita and Dr. Bustamante. As Mexico's Secretary of Public Health and Assistance, and Undersecretary of Public Health, respectively, for the 1958-1964 period, Dr. José Alvarez Amézquita and Dr. Miguel E. Bustamante unquestionably are the two top authorities on all aspects of medicine and public health in Mexico throughout their terms of office, and are experts on medical and public health history, as well. They collaborated in this book and contributed much to it.

In covering medical developments in Mexico, I became well acquainted with Dr. Amézquita and Dr. Bustamante. One day when I was doing some research at the Department of Public Health and Assistance, Sr. Gerardo d'Isolbi, the Department's director of public relations (and an editor of Siempre, Mexico's leading political publication), suggested that I write this book-an undertaking I already 
had in mind. A series of conferences with the Secretary and the Undersecretary followed. Dr. Amézquita and Dr. Bustamante were interested in collaborating in the book I proposed on medicine and public health in Mexico, presenting a panoramic view of past and present, based on a wide spectrum of governmental and nongovernmental sources-a book designed not only for Mexicans but for persons everywhere interested in Mexico and its achievements; not only for medical doctors and members of allied professions but for the general public.

Dr. Amézquita and Dr. Bustamante made available all the material derived from their department's facilities and archives and provided the benefit of their own great experience and knowledge in the field (much of which is included in their four-volume Historia de la Salubridad y de la Asistencia en México). Their personal support and cooperation continued during the writing. For their participation in this book I wish to express my sincere thanks and appreciation.

\section{EXTENT OF COVERAGE}

The first part of the book deals with medicine and public health in the Aztec era, ending with the Spanish Conquest in 1521; the second part covers the Spanish Colonial period, that continued until 1821; the third part brings the story of medicine in Mexico up to the present.

Records and statistics in government archives are complete through December 1, 1964.

That date marks the end of the administration of Mexico's President Adolfo López Mateos and the completion of that administration's integrated direction of six years of medical and public health programs. (Mexico's Presidents serve a single, six-year term; hence governmental planning has a sexenio, or sexennial, base.)

The administration of President Gustavo Díaz Ordaz is in its initial stage as this account is written and its records are not yet accessible. Only a few of its early statistics could be included.

As would be expected, however, most programs conducted by the Department of Public Health and Assistance during the López Mateos administration are being continued and advanced. 